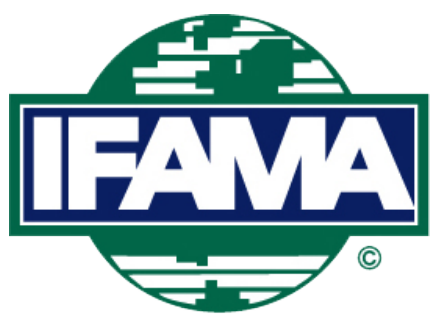

International Food and Agribusiness Management Review

Volume 24, Issue 1, 2021; DOI: 10.22434/IFAMR2019.0218

Received: 6 January 2020 / Accepted: 15 September 2020

\title{
Market simulations of consumer preferences for the introduction of GM tomatoes
}

\author{
RESEARCH ARTICLE \\ Joshua Berning ${ }^{\# \mathrm{a}}$ and Benjamin L. Campbel1 ${ }^{\sharp \mathrm{tb}}$ \\ ${ }^{a}$ Associate Professor, Department of Agricultural and Resource Economics, \\ Colorado State University, B337 Clark Building, Fort Collins, CO 80523, USA \\ ${ }^{b}$ Associate Professor, Department of Agricultural and Applied Economics, \\ University of Georgia, 147 Cedar St., Athens, GA 30602, USA \\ \# these authors contributed equally.
}

\begin{abstract}
Labeling of genetically modified (GM) foods has increasingly become a topic at the consumer and policymaker level. Using an online survey that included a conjoint analysis experiment, consumer preference for GM labeling on both fresh tomatoes and tomato plants was evaluated. Retailer (farmers market, grocery stores, mass merchandisers) sales and quantity sold were simulated to examine the impact of introducing GM labeling as well as certified GM labeling. Results indicate that retailers can increase revenues via price increases associated with the introduction of GM labeling.
\end{abstract}

Keywords: genetically modified, conjoint analysis JEL code: Q13

\footnotetext{
(i)Corresponding author: bencamp@uga.edu
} 


\section{Introduction}

Labeling genetically modified organisms (GMO) has been a contentious issue among consumers and producers in the US and abroad. On December $20^{\text {th }}, 2018$ the USDA announced the National Bioengineered Food Disclosure Law which will require labeling of all genetically modified and bioengineered foods by 2020 . Many proponents of GMO labeling are not satisfied with the law, however, indicating that the resulting labels will not clearly identify GM foods and will ultimately create more confusion (Organic Trade Association, 2019). This creates the opportunity for food processors and retailers to further distinguish their non-GMO foods with their own GMO-free labels. In fact, there is a growing effort by companies and organizations to differentiate their products using 'GMO-free' style labels, such as the Non-GMO Project (2019). In effect, these emphasize the absence of GMOs to contrast the proposed law that highlights the presence of GMOs.

Work on GMO labeling (Costanigro and Lusk, 2014; Liaukonyte et al., 2013) suggests that labels which identify the presence of GMOs (i.e. 'Contains GMOs') have a larger effect on consumer willingness to pay than labels which identify the absence of GMOs (i.e. 'GMO-free'). Further, Golan and Kuchler (2011) note that a strategy to promote non-GM foods will only be feasible if it is affordable to consumers, thus highlighting the price wedge between non-GM foods and the less expensive GM foods. Given the forthcoming change in the law and the growing use of GMO-free labels in retail markets, the purpose of this research is to examine what effect GMO-free labels, in conjunction with other marketing factors such as price discounts and marketing channel decisions, affect consumer demand.

The effect of GMO labels on consumers has been well-studied in the US and abroad, providing mixed findings and significant heterogeneity in consumer preferences (Costa-Font et al., 2008; Lusk et al., 2005). For instance, in a study of Canadian consumers, Heslop (2006) found minimal effect of GM labels. But reactions varied based on levels of consumer activism, perceived benefits and interest in novel foods. Noussair et al. (2002) found that consumers in France appeared not to notice GMO labels in an experimental auction. Once the label was highlighted, consumers bid significantly less for GM foods. However, given a price discount, consumers were still willing to purchase GM foods. And Noussair et al. (2003) found French consumers are willing to purchase GMOs if they are sufficiently inexpensive.

In Germany, Wuepper (2018) found a negligible average effect of GMO labels, but also found that consumers who are more accepting of GMOs tend to be younger, less educated and less concerned about their nutrition. Kalaitzandonakes et al. (2005) found that consumers in the Netherlands did not alter their purchases when labels were introduced into their market.

In their assessment of countries with GM labeling policies, Golan and Kuchler (2011) found that overall labels had a small effect on consumer choice, suggesting that labeling was a weak policy tool for changing consumer behavior. In particular, time-constrained consumers often make little use of information and fail to recognize GM labels.

To date, research on GMO labels has emphasized heterogeneous consumer preferences. The primary contribution of this research is to compare GMO labeling introductions on market share, quantity sold, and sales across retail outlets given varying price premiums. Notably, we estimate the impact of GMO-free labels on consumer demand while simultaneously considering effect of other marketing factors. To do so, a conjoint analysis (CA) of almost 1,400 consumers in Connecticut was conducted. Connecticut was the first state to approve labeling GM foods in 2013, although the law was never implemented. Using the results of the CA, the market was then simulated to examine the potential market outcomes given common marketing tactics.

A key assumption was that GMO labeled products will to some extent vertically differentiate from nonlabeled products. To this point, this study examined how price premiums paid for GMO labeled products affect consumer preferences. Clearly, demand was expected to decline as price increases, but the rate of decline has important implications for market share and revenues earned. 
Next, the effect of two GMO labels (GMO-free and Certified GMO-free) on consumer preferences was examined. Both labels help consumers to overcome the difficulty of identifying GMO products, which provides value to certain consumer segments. The latter label was assumed to offer a certain credibility that consumers might prefer and seek out. Thereby, this study examines how the price premium and GMO labels affect consumers shopping preferences across several marketing channels: farmers markets, grocery stores and mass merchandisers.

Finally, simulations using two products (fresh tomatoes and tomato plants) were compared. These produce the same end product; however, fresh tomatoes are ready-to-eat, whereas tomato plants require additional consumer effort before consumption. This comparison examines how such differences might impact consumer preferences for GMOs.

The results of the simulations highlight important considerations regarding the impact of GMO labeling on market share outcomes. As might be expected, there was a great amount of variation in the effect of GMOfree labels which is contingent on the marketing channel, certification of label, and associated price markups. This has important implications for understanding what impact GMO-free labels might have on retail markets. Of particular note, this study finds that due to inelastic preferences, even though higher prices for GMO-free drive down demand, total revenue was still increasing. Consequently, the promotion of GMO-free labels may incentivize retailers to raise prices resulting in lower demand for GMO-free products, ultimately creating an unintended consequence for advocates of GMO-free products.

\section{Methods}

During the summer of 2016, an online survey was implemented to examine consumer preference and knowledge of local, organic, and GMO labeling on food and non-food products. Respondents were obtained from the panel database of Global Market Insite, Inc. (GMI, Bellevue, WA, USA). Panelists were randomly selected to receive an invitation from GMI's panel database. The only precursor to participating was to be 18 years of age or older and to reside in Connecticut. The survey was limited to the state of Connecticut (CT) given the funding agency's desire to understand the CT market. However, CT does offer an interesting test case for a variety of reasons. Notably, CT enacted the first state-mandated GMO labeling laws in the U.S. (CGA, 2013). Even though this law, and other state-based GMO labeling mandates, have been nullified due to the signing of federal labeling requirements (Radelat, 2016), the fact that CT passed their own law shows they are at the forefront of the GMO debate. Furthermore, CT has made a commitment to local foods by implementing a plan to increase local food sales to $5 \%$ of total food sales by 2020 (CGA, 2011).

Panelists agreeing to participate were directed to the survey. A total of 1,374 panelists completed the conjoint section of the survey and demographics representing a $92 \%$ completion rate. Prior to entering the conjoint section of the survey, respondents were asked about their purchasing habits of fresh tomatoes or tomato plants (depending on which product they would evaluate in the conjoint section. However, only 500 panelists (318 purchased fresh tomatoes and 182 purchased tomato plants) were included in the final analysis because they indicated they were buyers of fresh tomatoes or tomato plants. Respondents were also reminded about to keep in mind their normal household budget constraints that they face when shopping for food. The sample is fairly representative of the CT population with respect to age, racial profile, gender and income (U.S. Census Bureau, 2011, 2015). The sample was slightly older (40 census vs 45 sample) than the CT population (U.S. Census Bureau, 2015). However, this comparison is misleading given the census includes all residents regardless of age, while our sample only included respondents over 18 years of age. Accounting for this difference aligns our sample's mean age with the CT population. Median household income is in-line with the CT population with the median sample household (U.S. Census Bureau, 2015). The one demographic that is out-of-line with the CT census is \% females in the sample. For this study, women were oversampled as they have been shown to more likely be the primary shoppers in households (Flagg et al., 2013; Wolfe, 2013; Zepeda, 2009). While the population is limited to CT, the takeaway messages are generalizable to other populations in so much as the data is representative of other areas. 
At the very least, the takeaway messages offer a glimpse into how varying markets will react to varying pricing schemes across retailers.

To examine consumer preferences, CA was utilized. CA has been used extensively for measuring preferences in both fruits and vegetables (Behe, 2006; Campbell et al., 2010, 2013, 2016; Darby et al., 2008; Ekelund et al., 2007; Frank et al., 2001; Onozaka and McFadden, 2011) and plants (Behe et al., 2005, 2014; Hall et al., 2010; Mason et al., 2008; Zagaden et al., 2008). A total of four products were examined in the CA, with fresh tomatoes and tomato plants being the focus of this paper. After agreeing to participate in the survey, respondents were randomly assigned to one of the four products to answer the CA question and purchasing behavior questions.

One of the first steps in CA is to identify the products, attributes, and levels to be evaluated. Important attributes identified via the literature were variety, price, retail location, product origin, production practices, and GMO label (Table 1). For each product four varieties were included: two highly demanded varieties, one variety with average demand, and a new variety with low demand. Specifically, beefsteak and cherry tomatoes are highly demand fresh/plant tomatoes, Brandy Wine has average demand and Sara Black is a relatively new variety with low demand.

The unit of measure was one-pint for fresh tomatoes and a four-inch container for the tomato plant. Prices were selected after examining local retail and online product pricing and were the same across products, ranging from $\$ 0.79$ to $\$ 4.69$. Retail locations consisted of mass merchandiser (e.g. WalMart, Target), grocery store, and farmers markets. With respect to product origin, there were five attribute levels: no label, New England, Canada, Connecticut, and California. These origins provide varying levels of geography, such as state, regional, and international. Production practices included no label, organic practices but not certified, certified organic, environmentally friendly, and sustainably grown.

Of keen interest to this paper was the impact of GMO labeling on consumer preference. Attribute levels for the GMO attribute included no label, GMO-free (but not certified), and Certified GMO-free. Within the experiment, the following wording was used: 'Certified GMO-free,' 'GMO free,' and no text included to indicate lack of labeling. Understanding the distinction between certification and non-certification is critical as many firms will be tasked with deciding whether to spend money to certify or not.

Table 1. Attributes and levels for the conjoint experiment.

\begin{tabular}{|c|c|c|c|c|c|}
\hline \multicolumn{6}{|c|}{ Fresh tomato (1 pint) } \\
\hline Variety & Price & Retail location & Product origin & Production practice & $\mathrm{GMO}^{1}$ label \\
\hline Brandy wine & $\$ 0.79$ & mass merchandiser & no label & no label & no label \\
\hline Cherry & $\$ 1.59$ & farmer's market & New England & organic practices, not certified & certified GMO-free \\
\hline Sara black & $\$ 2.39$ & grocery store & Canada & certified organic & GMO-free, not certified \\
\hline \multirow[t]{2}{*}{ Beef steak } & $\$ 3.59$ & & Connecticut & environmentally friendly & \\
\hline & $\$ 4.69$ & & California & sustainably grown & \\
\hline \multicolumn{6}{|c|}{ Tomato plant ( 4 in container) } \\
\hline Brandy wine & $\$ 0.79$ & mass merchandiser & no label & no label & no label \\
\hline Cherry & $\$ 1.59$ & farmer's market & New England & organic practices, not certified & certified GMO-free \\
\hline Sara black & $\$ 2.39$ & grocery store & Canada & certified organic & GMO-free, not certified \\
\hline \multirow[t]{2}{*}{ Beefsteak } & $\$ 3.59$ & & Connecticut & environmentally friendly & \\
\hline & $\$ 4.69$ & & California & sustainably grown & \\
\hline
\end{tabular}

$1 \mathrm{GMO}=$ genetically modified organisms. 
CA requires that respondents evaluate products consisting of one level of each attribute. Given the large number of attribute level combinations $\left(5^{3} \times 4^{2} \times 3\right)$, it would be infeasible for a respondent to evaluate all products derived from the combination of attribute levels. Therefore, a fractional factorial design was used to limit the number of products needed to be evaluated. Within the survey, respondents were asked to evaluate 25 products on a $0-100$ willingness to purchase scale $(0=$ extremely unlikely to purchase, $50=$ neither likely or unlikely, $100=$ extremely likely to purchase). Products were randomized to limit order bias. After completing the CA experiment, respondents were asked a purchase behavior question about the product they evaluated, followed by local, organic, and GMO purchase and perception questions as well as demographic questions.

CA is based on the theory that overall product valuations are made up of the utility associated with attributes and attribute levels that make up the product (Baker, 1998). A consumer's total product utility can be characterized as:

$$
\mathrm{U}_{\mathrm{im}}=\mathrm{V}_{\mathrm{im}}+\varepsilon_{\mathrm{im}}
$$

where, $\mathrm{U}$ is total produce utility for the $\mathrm{m}^{\text {th }}$ product of respondent $\mathrm{i}, \mathrm{V}$ is a vector or product attribute utilities, and $\varepsilon$ is a stochastic error term (Lusk and Schroeder, 2004). Utilizing individual regression models, partworth utilities were obtained by estimating the following model for each respondent:

$$
R T_{k i}=\sum_{i=1}^{25} X_{k} \beta_{k i}+\epsilon_{i}
$$

where, RT is the rating of product $\mathrm{k}$ of individual $\mathrm{i}, \mathrm{X}$ is a vector of effects coded attribute levels of product $\mathrm{k}, \beta$ represents a vector of coefficients (i.e. part-worth utilities), and $\varepsilon$ is a random error term. Effects coding requires the part-worth coefficients sum to zero, so the base (left out dummy variable) coefficient can be recovered. Relative importance values can then be calculated as:

$$
R I_{i}=\left(\text { range }_{i} / \sum_{i=1}^{6} \text { range }_{i}\right) \times 100
$$

where, RI represents the relative importance of the $\mathrm{i}^{\text {th }}$ attribute, range is the difference between the maximum and minimum coefficients for each attribute whereby there are six attributes (Hair et al., 1998). Relative importance can be thought of as the weight each attribute has on each consumer's buying decision.

\subsection{Labeling scenarios}

After computing the part-worth utilities, market shares, market demand (lb), and revenues (\$) for tomatoes and tomato plants were simulated based on several defined scenarios. The first choice model was applied in conjunction with CA as popularized by Bretton-Clark (1992). This technique has been used to simulate market scenarios in mandarin oranges (Campbell et al., 2006), peanuts (Nelson et al., 2005) and peaches (Campbell et al., 2013), among others. The first choice model is based on economic theory in that a consumer will choose the product with the highest utility. The market simulations are performed by adding or removing attribute levels from products to identify market shares based on utility.

With respect to market simulations, a market was established by adding varying products to the market. For the market simulations, the same tomato product (i.e. variety), price (\$2.39), CT origin, and no production label is used. These attributes, except for price, were held constant throughout the simulations. Given the attributes remained constant, their utilities are held constant across the various simulations allowing the impacts of changing GMO labeling, price, and retailer to be evaluated. In each of the scenarios, the price across retailers was kept equal at the beginning of the simulation with the only price change being from the systematic price premium added to GMO labeling. Given Salisbury et al. (2018) found some tomato varieties higher priced at farmers markets while other varieties were lowered priced compared to grocery stores, keeping equal average prices across retailers is consistent with the market for tomatoes. For each 
market simulation scenario, GMO labeling and/or retailers are then introduced into the market with price premiums added according to the specific scenario.

In order to assess how changing prices and labeling introductions would impact varying retailers in the market, changes in market share, revenues, and potential volume sold are assessed. Given basic microeconomic demand theory, a consumer would purchase the product with the highest total utility. Market shares were calculated based on the $\%$ of respondents choosing each product. The price premium of the GMO-free product was systematically increased by $10 \%$ (from 0 to 100\%) to assess how a higher price premium GMO-free product would impact demand. $10 \%$ was chosen as it allows researchers to systematically examine how price changes impact the market from no price change to a doubling of price, while also keeping the number of price variations manageable. To better assess demand and revenues, the respondent's answers to the purchasing questions (i.e. how many lb/plants purchase, when purchase, and how often purchase tomatoes) were utilized to identify how much a respondent would purchase per year ( $\mathrm{lb}$ for fresh tomatoes and number of plants for four-inch containers). Aggregate demand was then calculated by aggregating quantity across the products chosen. Multiplying quantity by product price gives revenue for each product. Own-price elasticities were calculated for each product at different price points from the base price. After assessing the two product (no label, GMO-free but not certified) model, a new product was added to the market (Certified GMO-free) and repeated the same analysis as the two-product simulation.

\section{Scenario 1: GMO-free label introduction with price premiums}

The purpose of the first scenario is to examine how the introduction of new information about GMO products might impact the market for fresh tomatoes and tomato plants; and how various price premiums further change market outcomes. This provides a baseline understanding of changes to markets with GMO products. The simulation started with $100 \%$ of the market comprised of a single product (fresh tomatoes or tomato plants depending on the simulation) with no information about GMOs. A GMO-free labeled product was then introduced to the market, holding all other attribute levels constant. Then the market was simulated with the same product introduction with a price premium for the GMO labeled product ranging from 10 to $100 \%$. Market share, demand (lb) and, and revenue for each level were then calculated.

\section{Scenario 2: Certified GMO-free label introduction with price premiums}

In the second scenario, the introduction of a Certified GMO-free label was explored to determine the impact a certified GMO-free label would have on a product with no label and products with GMO-free labels that are not certified. The purpose of this scenario was to understand the additional impact of a label that provides additional credibility for GMO claims. Currently, certain products are displaying 'GMO-free' labels even though the product is not known to contain GMOs to begin with. This can have the effect of watering down any relevant GMO-free claims. Presumably, a certified GMO-free label would require additional costs and effort to acquire. As such, a certified claim might imply that the distinction between labeled and unlabeled products is meaningful.

In this scenario, the simulation starts with a market consisting of products with no label and products with a GMO-free label. A certified GMO-free label was then introduced into the market, holding all other attribute levels constant. Then the price of the GMO-free and certified GMO-free products is increased by 10 to $100 \%$ and market shares, demand (lb) and revenues for each level were calculated.

\section{Scenario 3: GMO-free label introduction in farmers markets with price premium}

The introduction of GMO-free labeled products does not appeal to all consumers the same. Further, their introduction may be more prominent in certain marketing channels that have more receptive consumers. Given varied preferences for both GMO-free products and marketing channels, this study considers the impact of the introduction of a GMO-free label for products sold at farmers markets only. First, simulations 
for an unlabeled product sold in three marketing channels is conducted: mass merchandiser, grocery store, and farmers markets. A GMO-free label was then introduced to the farmers market channel only. Again, increasing price premiums with the new product introduction was examined.

\section{Scenario 4: Certified GMO-free label introduction in all marketing channels with price premiums}

Building off of scenario 3, a certified GMO-free label was introduced into farmers markets. Specifically, the initial market includes three marketing channels and a GMO-free label only in the farmers market marketing channel. Then, the impact of adding a certified GMO-free label to the farmers market was examined. This was intended to examine the impact of certification on non-verifiable GMO claims.

\section{Scenario 5: Certified GMO-free label introduction in all marketing channels with price premiums}

Finally, the introduction of both GMO-free and certified GMO-free labels in all three marketing channels was examined. Initially, the simulation consisted of a market with three marketing channels (mass merchandisers, grocery stores and farmers markets), and products with no labels and a GMO-free label sold in farmers markets only. Then, a GMO-free label was introduced in mass merchandisers and grocery stores. Next, a certified GMO-free label was introduced across all marketing channels. Price premium increases for both GMO labels were examined in all marketing channels. That is, not only do the GMO-free label products have higher prices in farmers markets, but in mass merchandisers and grocery stores as well. The purpose of this simulation was to understand the impact of a more 'mature' product market where multiple channels carry all available GMO-free products. This was used to provide a long-term perspective on the market for GMOs.

\section{Results}

\subsection{Conjoint analysis results}

Based on the CA results, price is the largest driver in the decision to purchase both fresh tomatoes and tomato plants. Specifically, price accounts for 27 and $23 \%$ of the purchase decision, respectively (Table 2). For both products, tomato variety is the second most important attribute at around 22\%. Shopping location, origin, and production practice have approximately the same impact on the decision to purchase making up between $11-17 \%$ of the purchase decision. GMO labeling has the smallest impact on the purchase decision for both fresh tomatoes and tomato plants. With respect to differences between fresh tomatoes and tomato plants, price is more important for fresh, while origin and production practices are more important for plants compared to fresh.

Evaluating part-worth utilities for fresh tomatoes, the beef steak tomatoes generate the highest part-worth utility gain (5.33 on the 100-point scale) with Sara Black generating a 11.3 reduction in utility. Respondents

Table 2. Relative importance values from the conjoint analysis by product type. ${ }^{1,2}$

\begin{tabular}{lllllll}
\hline & Fresh & \multicolumn{7}{l}{ Plants } \\
\hline Attribute & Relative importance & $90 \%$ CI & Relative importance & $90 \%$ CI \\
Tomato variety & $21.5 \%$ & $20.0 \%$ & $23.0 \%$ & $21.9 \%$ & $20.1 \%$ & $23.8 \%$ \\
Price & $27.9 \%$ & $26.4 \%$ & $29.5 \%$ & $22.7 \%$ & $21.1 \%$ & $24.3 \%^{* * *}$ \\
Shopping location & $11.7 \%$ & $10.7 \%$ & $12.6 \%$ & $13.0 \%$ & $11.6 \%$ & $14.4 \%$ \\
Origin & $15.5 \%$ & $14.7 \%$ & $16.3 \%$ & $16.8 \%$ & $15.8 \%$ & $17.7 \%^{*}$ \\
Production practice & $14.6 \%$ & $14.0 \%$ & $15.2 \%$ & $16.1 \%$ & $15.3 \%$ & $16.9 \%^{* *}$ \\
GMO & $8.8 \%$ & $8.2 \%$ & $9.4 \%$ & $9.6 \%$ & $8.8 \%$ & $10.3 \%$ \\
\hline
\end{tabular}

${ }^{1} \mathrm{GMO}=$ genetically modified organisms; $\mathrm{CI}=$ confidence interval.

$2 *, * *$, and $* * *$ represents significance at the $0.01,0.05$, and 0.1 levels, respectively. 
also preferred, as expected, lower prices to higher prices. Farmers markets and grocery stores generated positive utility while mass merchandisers had a negative utility associated with them. Also, as expected Connecticut tomatoes produced the highest utility increase with Canadian product decreasing utility by 3.2 points on the 100-point scale. Also, of interest, organic produced a negative utility while certified organic generated positive utility. Finally, both the GMO-free and certified GMO-free labels generated similar partworth utility gains (Table 3 ).

With respect to tomato plants, the part-worth utility results were similar to the fresh tomato results in sign. Comparing the fresh tomato and tomato plant part-worth utilities showed that cherry tomatoes were preferred more for fresh tomatoes while Sara Black tomatoes were not as heavily discounted as tomato plants. Furthermore, tomato plant buyers did not penalize higher prices as much as fresh tomato buyers.

Table 3. Part-worth utilities from the conjoint analysis by product type. ${ }^{1,2}$

\begin{tabular}{|c|c|c|c|c|c|c|}
\hline Type & Part-worth mean & $90 \% \mathrm{CI}$ & & Part-worth mean & $90 \% \mathrm{CI}$ & \\
\hline Constant & 52.82 & 51.17 & 54.47 & 54.54 & 52.15 & 56.92 \\
\hline \multicolumn{7}{|l|}{ Tomato variety } \\
\hline Brandy wine & 3.46 & 2.62 & 4.30 & 2.94 & 1.73 & 4.14 \\
\hline Cherry & 2.48 & 1.31 & 3.65 & -1.48 & -3.20 & $0.24 * * *$ \\
\hline Sara black & -11.27 & -12.82 & -9.71 & -7.84 & -9.64 & $-6.05 * *$ \\
\hline Beef steak & 5.33 & 4.37 & 6.29 & 6.39 & 4.89 & 7.88 \\
\hline \multicolumn{7}{|l|}{ Price } \\
\hline$\$ 0.79$ & 15.32 & 13.77 & 16.88 & 7.94 & 6.07 & 9.80 \\
\hline$\$ 1.59$ & 8.11 & 6.98 & 9.24 & 5.35 & 3.97 & $6.72 * *$ \\
\hline$\$ 2.39$ & 0.41 & -0.40 & 1.23 & 1.19 & 0.15 & 2.23 \\
\hline$\$ 3.59$ & -8.65 & -9.77 & -7.53 & -5.13 & -6.46 & $-3.80 * * *$ \\
\hline$\$ 4.69$ & -15.20 & -16.65 & -13.74 & -9.34 & -11.03 & $-7.65 * * *$ \\
\hline \multicolumn{7}{|l|}{ Retail location } \\
\hline Mass merchandiser & -4.46 & -5.42 & -3.51 & -2.79 & -3.94 & $-1.65^{*}$ \\
\hline Farmers' market & 3.63 & 2.71 & 4.55 & 4.40 & 2.95 & 5.84 \\
\hline Grocery store & 0.83 & 0.21 & 1.45 & -1.60 & -2.52 & $-0.69 * * *$ \\
\hline \multicolumn{7}{|l|}{ Origin } \\
\hline No origin & -1.68 & -2.45 & -0.91 & -1.56 & -2.48 & -0.63 \\
\hline New England & 2.78 & 2.08 & 3.49 & 2.28 & 1.22 & 3.34 \\
\hline Canada & -3.17 & -4.05 & -2.29 & -2.92 & -4.23 & -1.62 \\
\hline Connecticut & 4.98 & 4.12 & 5.84 & 4.88 & 3.72 & 6.04 \\
\hline California & -2.91 & -3.67 & -2.16 & -2.68 & -3.77 & -1.60 \\
\hline \multicolumn{7}{|l|}{ Production labels } \\
\hline No label & -1.65 & -2.36 & -0.94 & -1.56 & -2.70 & -0.41 \\
\hline Organic practices & -1.15 & -2.11 & -0.20 & -2.43 & -3.62 & -1.25 \\
\hline Certified organic & 1.45 & 0.51 & 2.39 & 2.20 & 1.17 & 3.23 \\
\hline Environmentally friendly & 1.25 & 0.57 & 1.92 & 1.70 & 0.73 & 2.67 \\
\hline Sustainable & 0.11 & -0.59 & 0.81 & 0.09 & -0.91 & 1.09 \\
\hline \multicolumn{7}{|l|}{ GMO labels } \\
\hline No GMO label & -1.94 & -2.66 & -1.23 & -1.75 & -2.63 & -0.88 \\
\hline GMO-free & 0.85 & 0.28 & 1.42 & 0.94 & 0.15 & 1.73 \\
\hline Certified GMO-free & 1.09 & 0.40 & 1.79 & 0.81 & -0.19 & 1.82 \\
\hline Adjusted R-squared & 0.60 & & & 0.45 & & \\
\hline Observations & 318 & & & 182 & & \\
\hline
\end{tabular}

${ }^{1} \mathrm{GMO}=$ genetically modified organisms; $\mathrm{CI}=$ confidence interval.

$2 *, * *$, and $* * *$ represents significance at the $0.01,0.05$, and 0.1 levels, respectively. 
Finally, fresh tomato buyers were more accepting of purchasing at grocery stores, while plant buyers were more accepting of plants available at mass merchandisers.

\subsection{Scenario 1: GMO-free label introduction with price premiums}

In the first scenario, the initial market was entirely comprised of products with no labels. With the introduction of the GMO-free label, the market share for unlabeled products declines by 53\% (100 to 47\%) for fresh tomatoes and 55\% (100 to 45\%) for tomato plants (Figure 1). Similar results occur with demand and revenues. Such a large decline in market share reveals strong consumer preferences for GMO-free labeled products in our survey sample (Figures 2 and 3).

Next, the impact of having GMO-free products introduced with price premiums was considered. As should be expected, market share and demand for GMO-free products was lower the higher the price premium (Figures 2 and 3). The impact of price premiums was more extreme with GMO-free fresh tomatoes than GMO-free tomato plants. For example, a 10\% price premium led to an $8 \%$ loss in market share for GMO-free fresh tomatoes compared to no price premium. Whereas GMO-free tomato plants only decline by $5 \%$ with the same price premium. Further, with higher price premiums the effect was much larger for GMO-free fresh tomatoes compared to GMO-free tomato plants. For example, the demand for GMO-free fresh tomatoes went from $11,000 \mathrm{lb}$ to $6,000 \mathrm{lb}(45 \%$ decrease $)$ with a $100 \%$ price premium. Tomato plants decreased from 738 plants to 446 plants ( $39 \%$ decrease) with the same price premium.

A

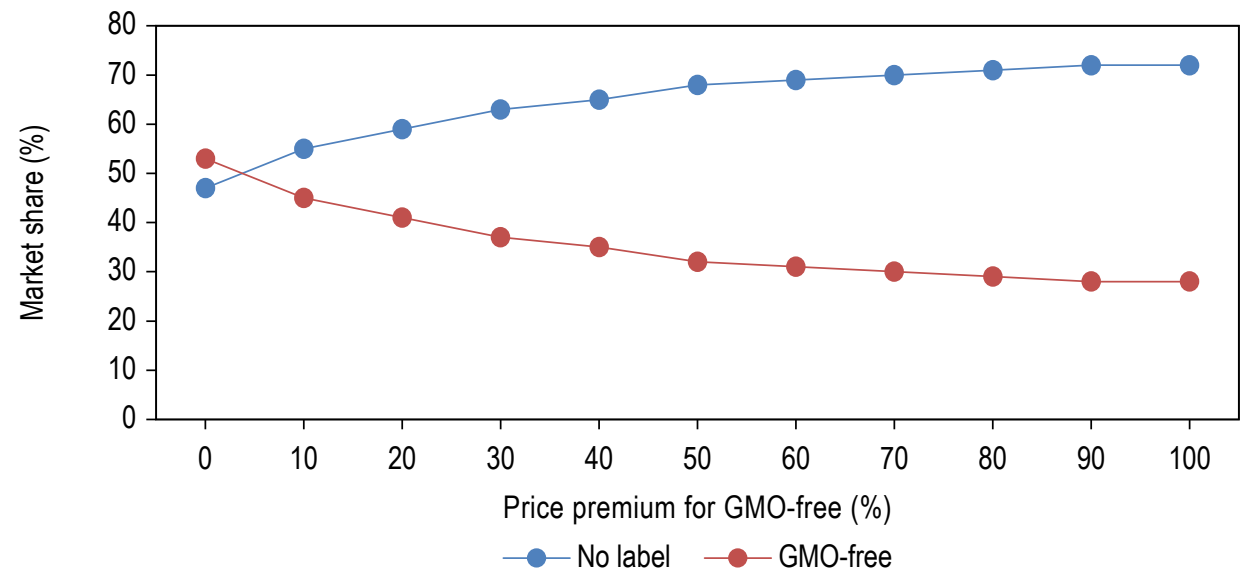

B

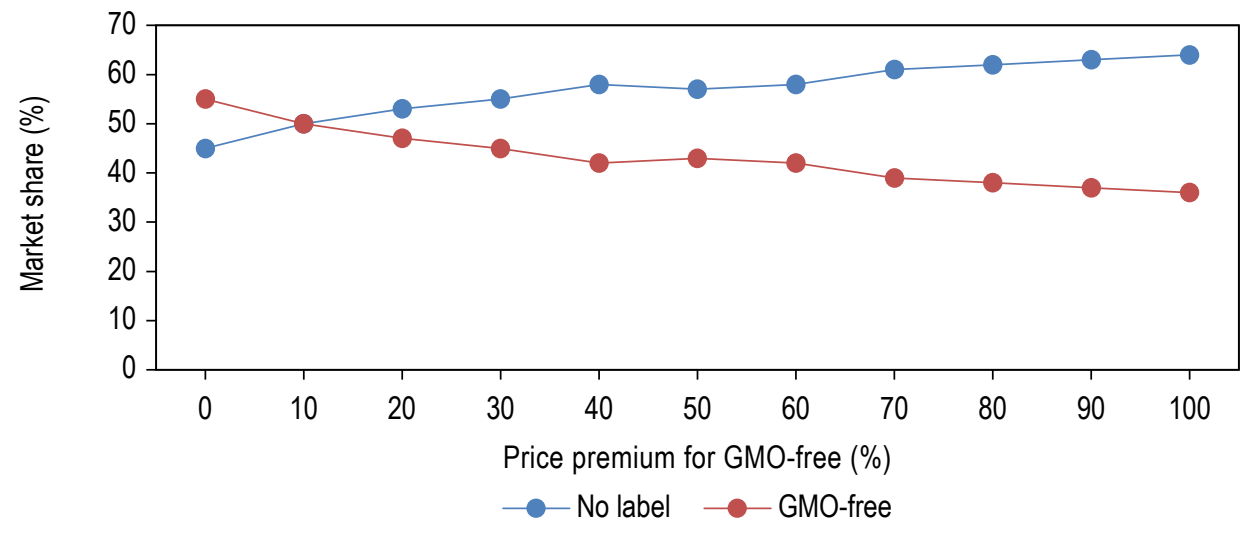

Figure 1. Market share for fresh tomatoes (A) and tomato plants (B) given a GMO-free product introduction at various price premiums above a non-GMO labeled product. 
A

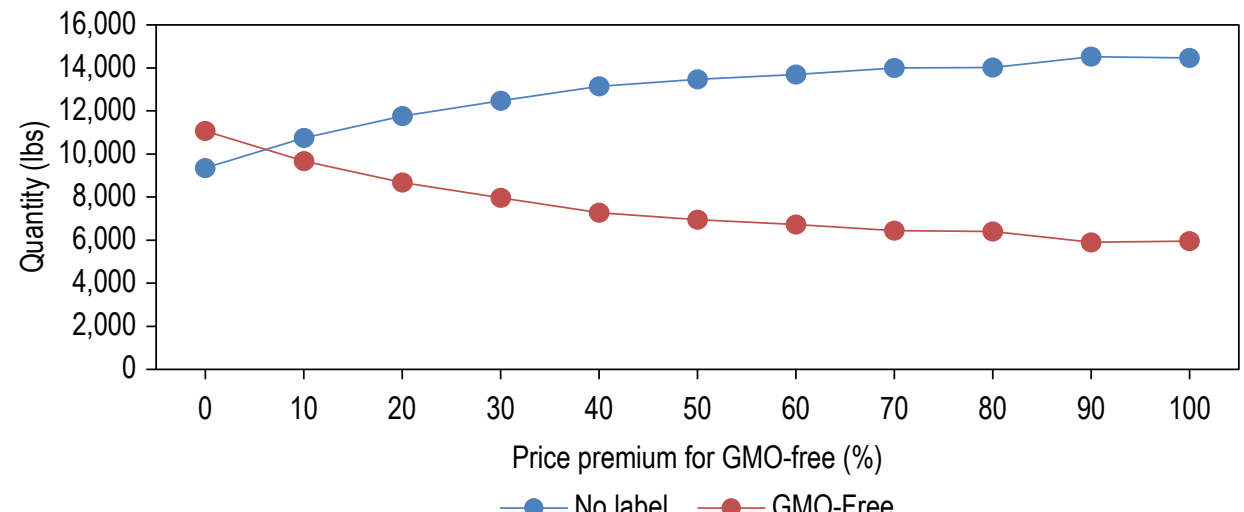

B

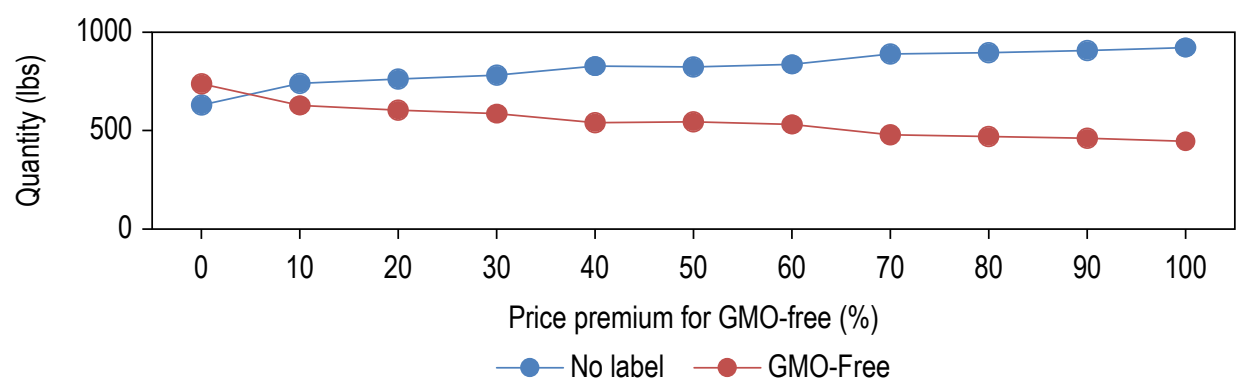

Figure 2. Quantity sold for fresh tomatoes (A) and tomato plants (B) given a GMO-free product introduction at various price premiums above a non-GMO labeled product.

A

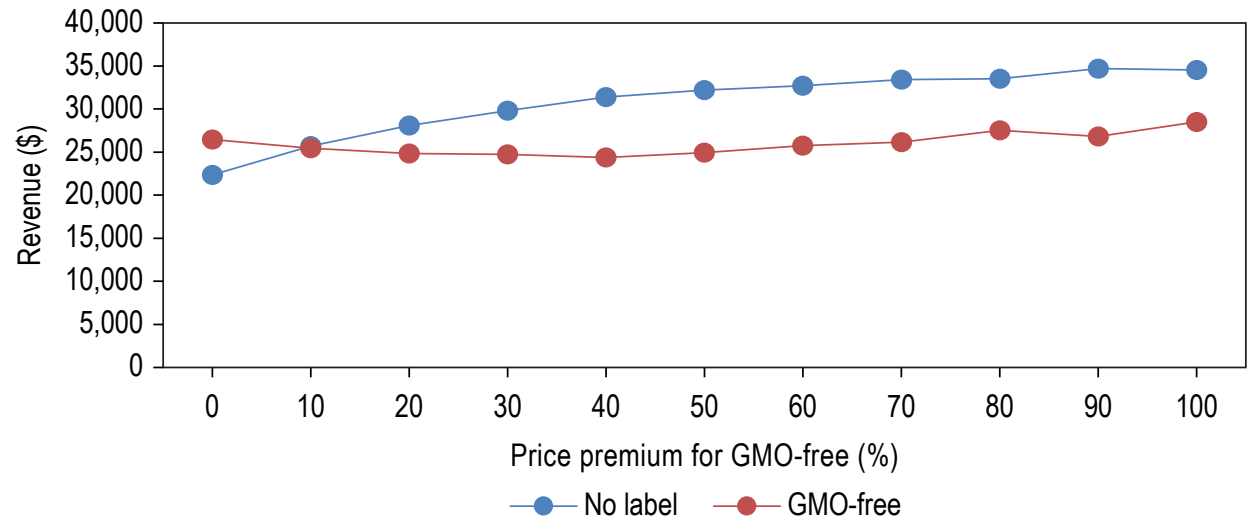

B

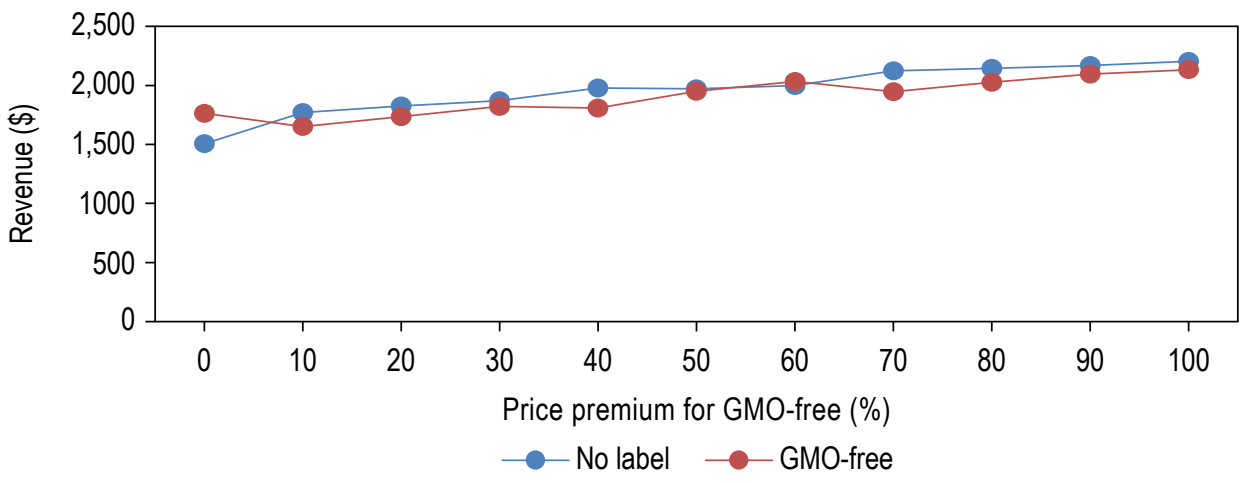

Figure 3. Revenue for fresh tomatoes (A) and tomato plants (B) given a GMO-free product introduction at various price premiums above a non-GMO labeled product. 
The change in revenues reveals an important consideration for these products. With GMO-free fresh tomatoes, revenues were the lowest when the price premium was $40 \%$ (i.e. \$24,000). With higher price premiums, however, the revenues grew larger. This reveals that demand was more inelastic with higher price premiums (Table 4). As a result of the change in elasticity, the loss in demand from higher price premium was more than offset by the price premiums. This is notable for retailers setting prices for GMO-free products: a price premium may not necessarily be detrimental to revenues given a less elastic consumer price response.

With GMO-free tomato plants, the lowest revenues are calculated at a $10 \%$ premium. This was due to the highly inelastic demand (Table 4). In fact, the 100\% price premium for GMO-free tomato plants resulted in the highest revenue. As a reference point, Consumer Reports found that organic food was $47 \%$ more expensive on average than non-organic (Consumer Reports 2015). This was for 100 products with a large variation in price premiums, so the reference should be taken lightly.

\subsection{Scenario 2: Certified GMO-free label introduction with price premiums}

In this scenario, the simulation demonstrates the effect of introducing a certified GMO-free label into a market that already has unlabeled products and products that are labeled GMO-free, but not certified (Figures 4, 5 and 6). The results indicate that introducing the certified GMO-free tomatoes more greatly reduces market share for unlabeled tomatoes than GMO-free tomatoes. Specifically, GMO-free lost about 12\% whereas unlabeled lost about $18 \%$. This shows that consumers who will not switch to GMO-free tomatoes switched to certified GMO-free tomatoes. Further, a sizeable share of consumers switched from GMO-free to certified GMO tomatoes. This highlights the potential benefit of a certification system for identifying GMO products. However, the unlabeled tomatoes gained back their entire market share when both the certified GMO product and the GMO-free product included at least a $20 \%$ premium. A variety of price premium combinations for the GMO-free and certified GMO-free products could have been considered, but this study only considered a common price premium for both products.

The market shares for tomato plants exhibited slightly different patterns. The unlabeled plants lost about $18 \%$ market share with the certified GMO-free introduction, whereas the GMO-free plants lost about 19\% market share (Figure 4). This suggests the certified GMO-free matters more than the uncertified GMO-free. A larger price premium associated with a GMO labeled product was needed for the unlabeled plants to regain their market share, about $40 \%$. Further, even with a $100 \%$ price premium for certified GMO-free, the unlabeled plants gained only a little over half the market share. This is contrary to what might be expected. Initially, the expectation was that consumers would be more price inelastic with tomatoes they consume rather than tomatoes they grow. But with our sample, this does not appear to be the case.

Table 4. Demand elasticities associated with a GMO-free label introduction for both products. ${ }^{1}$

\begin{tabular}{|c|c|c|c|c|}
\hline \multirow[b]{3}{*}{ Price premium } & \multicolumn{4}{|c|}{ Elasticities } \\
\hline & \multicolumn{2}{|l|}{ Fresh } & \multicolumn{2}{|l|}{ Plants } \\
\hline & No label & GMO-free & No label & GMO-free \\
\hline $10 \%$ & 1.49 & 1.26 & 1.75 & 1.49 \\
\hline $20 \%$ & 1.28 & 1.08 & 1.06 & 0.90 \\
\hline $30 \%$ & 1.11 & 0.94 & 0.80 & 0.69 \\
\hline $40 \%$ & 1.01 & 0.85 & 0.79 & 0.67 \\
\hline $50 \%$ & 0.88 & 0.74 & 0.62 & 0.53 \\
\hline $60 \%$ & 0.77 & 0.65 & 0.54 & 0.47 \\
\hline $70 \%$ & 0.71 & 0.60 & 0.59 & 0.50 \\
\hline $80 \%$ & 0.62 & 0.53 & 0.53 & 0.45 \\
\hline $90 \%$ & 0.61 & 0.52 & 0.49 & 0.42 \\
\hline $100 \%$ & 0.55 & 0.46 & 0.46 & 0.40 \\
\hline
\end{tabular}

${ }^{1} \mathrm{GMO}=$ genetically modified organisms. 
A

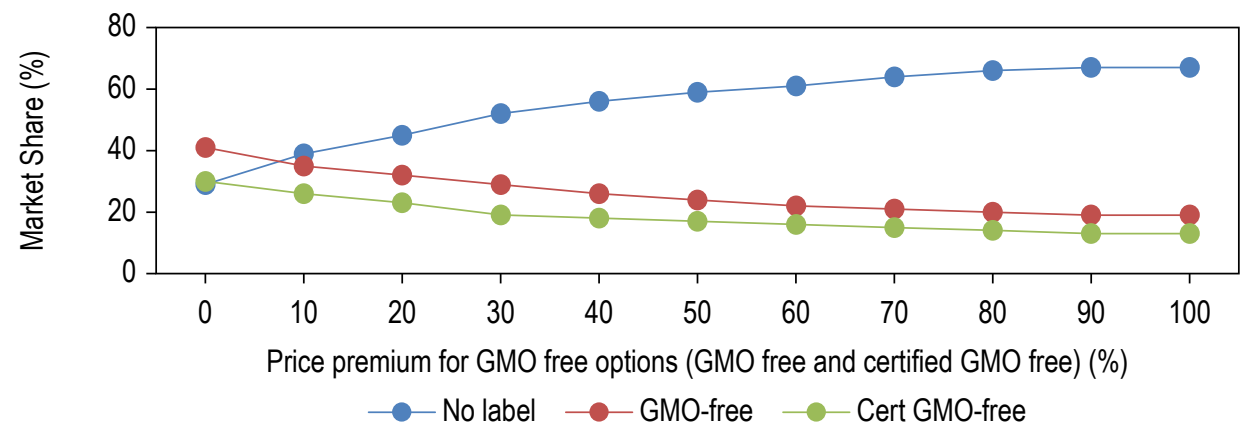

B

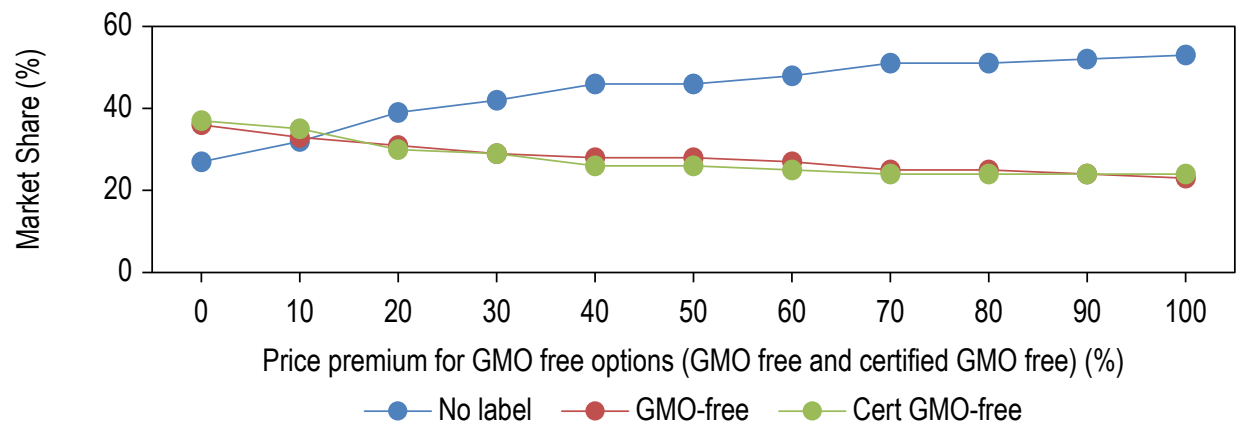

Figure 4. Market share for fresh tomatoes (A) and tomato plants (B) given a GMO-free and certified GMOfree product introduction at various price premiums above a non-GMO labeled product.

The demand for unlabeled tomatoes was larger with higher price premiums for GMO tomatoes and the demand for both GMO-free and certified GMO-free declined with higher price premiums (Figure 5). Similar trends were found for tomato plants. The revenues for the three products display some interesting trends resulting from survey respondent preferences. With the introduction of the certified GMO-free tomatoes, unlabeled tomatoes lost around $\$ 7,000$ in revenues. But with a $20 \%$ price premium, their revenues returned to their base levels. With higher price premiums, unlabeled tomatoes gained significantly in revenues.

At the same time, the GMO-free and certified GMO-free tomatoes maintained fairly consistent revenues even with the higher price premiums (Figure 6). Again, this was due to the inelastic demand for GMO-free products at higher prices. Importantly, the revenues exhibited non-monotonic jumps with the various price premiums. This was a result of the preference structures of certain consumers in our sample. Specifically, certain consumers switched to GMO-free tomatoes at higher prices, which could be the result of price premiums being validation for the GMO-free aspect of the product. With tomato plants, both GMO-free and certified GMO-free had their largest revenues with the highest price premiums. In fact, total revenues for tomato plants were largest when both GMO-free plants had the highest price premiums.

\subsection{Scenario 3: GMO-free label introduction in farmers markets with price premium}

In this simulation, the initial market share, demand, and revenues for tomatoes favored the farmers market marketing channel even with no GMO-free product offered (Supplementary Table S1). When the GMOfree label was introduced in the farmers market channel, total market share declined for the other marketing channels and grew for the farmers market from 50 to $64 \%$ (20+44\%). However, there was cannibalization of market share for the unlabeled tomatoes sold at the farmers market, which dropped from 50 to $20 \%$. The same occurred with demand and revenue.

With higher price premiums for GMO-free tomatoes, market share and demand declined. Interestingly, the market-share and demand at mass merchandisers and grocery stores recovered only moderately. At the same time, the market share and demand for unlabeled tomatoes at the farmers market recovered the most. This reflects consumer preferences for the farmers market marketing channel. 
A

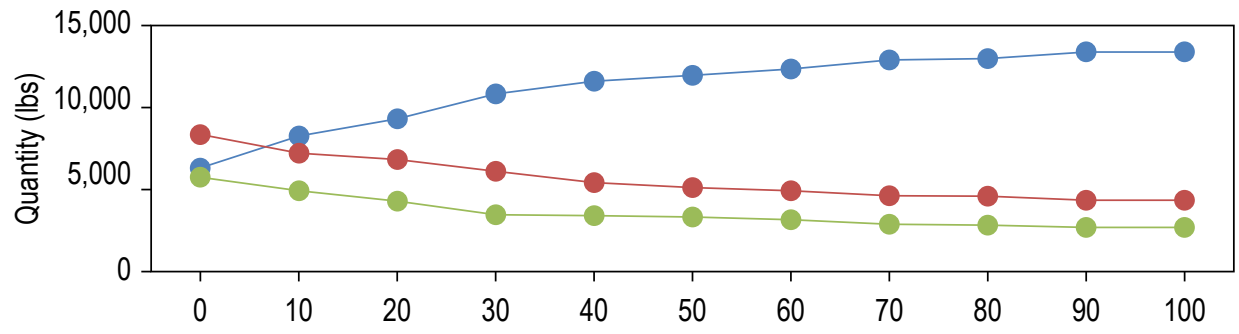

Price premium for GMO free options (GMO free and certified GMO free) (\%)

B

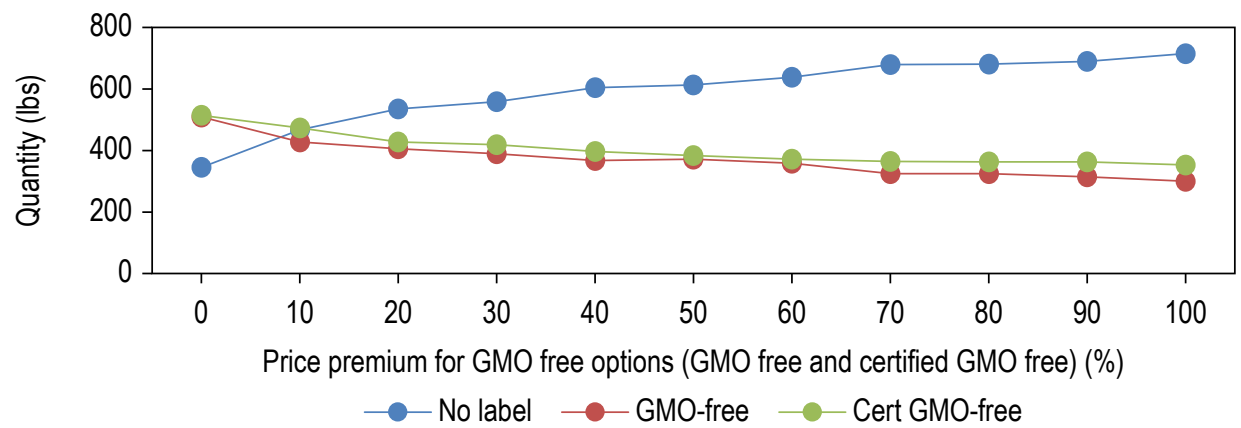

Figure 5. Quantity sold for fresh tomatoes (A) and tomato plants (B) given a GMO-free and certified GMOfree product introduction at various price premiums above a non-GMO labeled product.

A

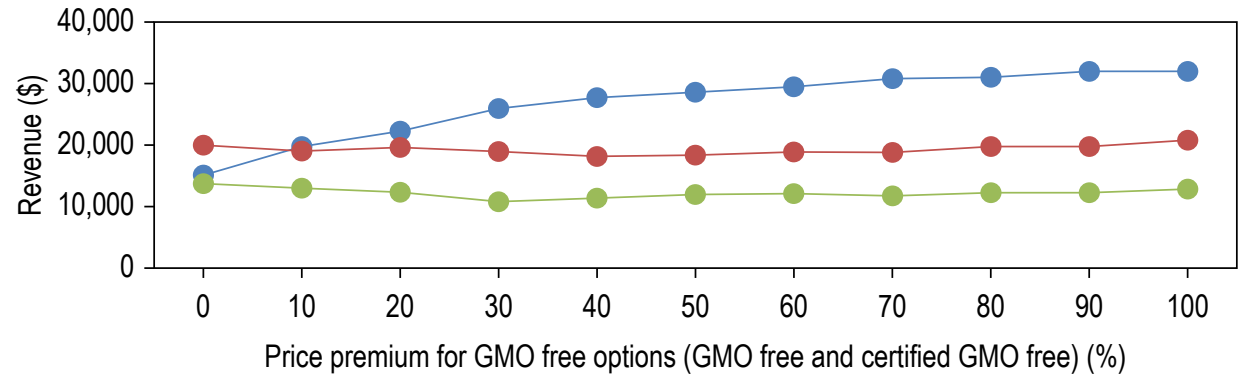

B

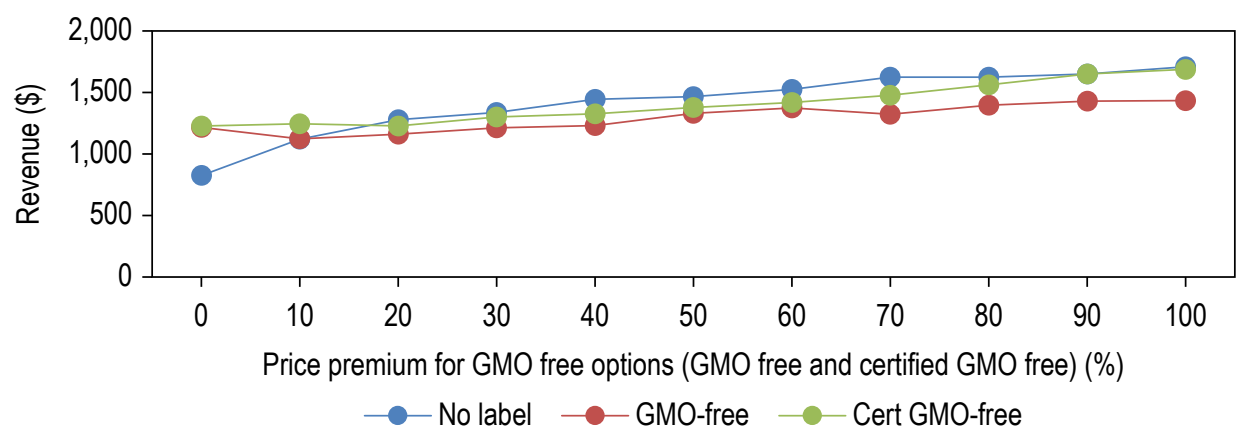

Figure 6. Revenue for fresh tomatoes (A) and tomato plants (B) given a GMO-free and certified GMO-free product introduction at various price premiums above a non-GMO labeled product.

With higher price premiums for the GMO-free offered at the farmers market, the mass merchandiser and grocery store acquired higher revenues due to consumers switching to the cheaper products. However, the revenues for the mass merchandiser and grocery store did not increase monotonically with price premiums. This was due to consumer preferences leading to switching across products and marketing channels. 
The revenues at the farmers market were strictly increasing with the price premiums. Ultimately, the revenues for the farmers market marketing channel were highest when GMO-free tomatoes charged the highest premium. The unlabeled tomatoes received over $\$ 16,000$ and the GMO-free received over $\$ 24,000$. While higher prices cause consumers to move from GMO-free labeled tomatoes, they did not leave the farmers market marketing channel. Further, revenues from consumers that still purchased GMO-free tomatoes at the higher prices, more than made up for the loss in demand.

With tomato plants, similar trends were observed as the farmers market market share remained high even with higher price premiums. Specifically, after the GMO-free introduction, the farmers market market share was roughly $64 \%(21+43 \%)$. Even with a $100 \%$ premium, the farmers market market share was still $60 \%$. Again, this was also reflected in the revenues where the highest revenues for the farmers market occurred when there was a $100 \%$ price premium.

\subsection{Scenario 4: Certified GMO-free label introduction in all marketing channels with price premiums}

Introduction of the certified GMO-free tomatoes at the farmers market led to the greatest reduction in GMO-free tomatoes at the farmers market followed by unlabeled tomatoes sold at the farmers market (Supplementary Table S2). The introduction of price premiums for the GMO-free and certified GMO-free products was associated with greater loss in market share for those products, especially the GMO-free tomatoes. This loss in market share was largely recovered by the unlabeled tomatoes in the farmers market rather than in the other marketing channels.

In this case, the price premiums significantly raised the revenues of GMO-free or certified GMO-free tomatoes as much as the previous scenarios. While the total revenues for the farmers market were the largest when both GMO-free products had the $100 \%$ price premium, the revenues were supported largely by unlabeled tomatoes as well as GMO-free tomatoes.

With tomato plants, the introduction of certified GMO-free most impacted the market share for GMOfree and unlabeled tomato plants sold through the farmers market. The price premiums for the GMO-free and certified GMO-free plants also tended to benefit the unlabeled plants sold through the farmers market channel. The GMO-free and certified GMO-free plants tended to have higher revenues with the given price premiums. The unlabeled plants in all marketing channels benefited as well.

\subsection{Scenario 5: Certified GMO-free label introduction in all marketing channels with price premiums}

The final scenario explored the impact of introducing GMO-free and certified GMO-free products across several marketing channels (Supplementary Table S3). Again, this was most representative of a mature market where multiple channels carry a variety of products. Initially, the GMO-free tomatoes sold in the farmers market dominate market share, sales and revenues across all product-market combinations. The introduction of GMO-free into the mass merchandiser and grocery store causes a loss in market share for GMO-free at the farmers market. That is, consumers that favor the GMO-free, but not necessarily farmers markets, transitioned to the other marketing channels. At the same time, unlabeled tomatoes sold at mass merchandisers and grocery stores also lost market share. In this case, consumers who shopped primarily at mass merchandisers and grocery stores transitioned to GMO-free products. The unlabeled tomatoes sold at farmers markets were unaffected. These were consumers that strictly preferred shopping through the farmers market marketing channel.

Next, we examined the additional impact of introducing certified GMO-free tomatoes across all of the marketing channels. In the farmers market channel, the GMO-free tomatoes lost the largest market share to the certified GMO-free tomatoes. However, in the mass merchandiser and grocery store, the unlabeled tomatoes lost the greatest market share to the introduction of the certified GMO-free tomatoes. 
Across all marketing channels, the unlabeled tomatoes lost the greatest market share to the certified GMO-free tomatoes. Specifically, with just the GMO-free and unlabeled tomatoes, unlabeled tomatoes had $47 \%$ market share. When certified GMO-free are introduced, this dropped to 29\%. GMO-free dropped from 54 to $41 \%$. This again shows the potential value in certified labels for consumers that typically select unlabeled tomatoes.

The impact of introduction with a price premium was primarily seen in the farmers market marketing channel. In general, unlabeled products gained greater market share and GMO-free lost market share with higher price premiums for the GMO-free products. Further, this change was largest in the farmers market channel. The overall reduction in market share for the GMO-free products was minimal in the other two marketing channels. The reduction in certified GMO-free products was also relatively small across the three distribution channels.

With revenues there were two important findings. First, the introduction of the new products only redistributed revenues across products and marketing channels. In fact, there was a slight decline in total revenues generated. The second finding was that total revenues were the largest with the highest price premium. Overall, all three marketing channels had greater revenues as well with the highest price premium.

With tomato plants, the introduction of GMO-free into the mass merchandiser and grocery store caused a large loss in market share for GMO-free at the farmers market. Specifically, market share fell from 43 to $30 \%$. Unlabeled tomatoes sold at mass merchandisers and grocery stores also lost market share. Interestingly, the unlabeled tomato plants sold at farmers markets held market share as these are consumers that did not value GMO-free labeling, but wanted to purchase at a farmers market.

After introducing certified GMO-free tomato plants across all of the marketing channels, the unlabeled plants sold at farmers markets now lost market share. The biggest gain in market share went to the certified GMO-free tomato plants sold at the farmers market. The GMO-free tomato plants at the farmers market lost just a small 1\% of market share with the certified GMO-free tomato plant introduction. Across all marketing channels, the unlabeled tomato plants lost the greatest market share to the certified GMO-free tomatoes.

The impact of introducing the GMO-free and certified GMO-free plants with a price premium was less pronounced. In general, unlabeled products in all marketing channels gained greater market share with higher price premiums for the GMO-free products. The reduction in market share for the GMO-free products was fairly evenly distributed across both the GMO-free and certified GMO-free products and across the various distribution channels.

Revenues reveal the same patterns as were found with tomato plants: the introduction of the new products redistributed revenues across products and marketing channels; total revenues were the largest with the highest price premium. One difference was that certified GMO-free revenues were lower at mass merchandisers with the $100 \%$ price premium. The certified GMO-free revenues were only slightly larger at grocery stores with the $100 \%$ premium. So, while the product had higher total revenues with higher price premiums, there may be opportunities to price differently based on marketing channels.

\section{Implications}

The findings of our CA and subsequent market simulations highlights important considerations for the use of GMO labeling in retail markets. Across all our results, there was a great amount of variation in the effect of GMO-free labels contingent on the marketing channel, certification of label, and associated price mark-ups. Heterogeneous preferences found in our results suggest multiple niche marketing opportunities. Producers may find it advantageous to market their products via certain market channels. Similarly, both retailers and producers may have varying incentives to promote their product lines using product labeling. While this is intuitive, we highlight a few specific findings. 
First, it seems that certification of the GMO label plays an important role in how consumers make their decisions. As previously mentioned, there is only one certified GMO-free label in the market of any scale, but food producers often put their own uncertified claims on their packaging. The additional certification may play an important role in certain marketing channels. Having said that, certification can often be a costly process both in terms of time and money and the impact it has on supply channels. Producers and retailers seeking to differentiate themselves using certified labels need to be cognizant of such costs.

A further consideration is that the value of certification may be stronger for certain products. We find that while fresh tomatoes and tomato plants have similar responses in our simulations, the results indicate that certified GMO free will impact unlabeled fresh tomatoes more than uncertified GMO free. That is, consumers prefer to consume GMO free, whether the claim is certified or not. But with tomato plants, consumers tend to prefer certified GMO free over uncertified claims.

In addition, interesting consumer preferences for channel or product were identified. In particular, consumers that like to shop at farmers markets, tend to not change their marketing channel, but instead change which products they select at farmers markets relative to price increases. Alternatively, consumers that prefer to shop for GM free products will switch marketing channels and pursue the certified GM free products. This highlights how marketing channel attributes may interact with product attributes to affect consumer preferences. As such, a one size fits all marketing approach may not be optimal for certain products.

Finally, price naturally plays a role in the outcomes of our simulations, but the net effect of price increases was a bit surprising. Due to inelastic preferences, price increases often lead to the highest total revenues across products and markets. This suggests that while price wedges between GMO-free and unlabeled products may emerge, they may not necessarily hurt the retailer's bottom line. Of course, in a competitive market, prices tend to be more elastic. So, firms need to first be aware of the price responsiveness of their consumer base before attempting to maximize profits in this fashion.

Beyond firm profits, such price elasticity could result in unintended market outcomes resulting from the promotion of GMO-free labels: prices for GMO-free remain high thus preventing certain consumers from switching to those products. Ultimately, the GMO-free label could end up being more beneficial for the firm than the advocate of GMO-free labeling.

Altogether, our findings suggest that marketing opportunities for GM products may be much more nuanced across multiple dimensions. This is, to some extent, in contrast to previous work finding a shift in willingness to pay arising solely from GM labeling.

\section{Supplementary material}

Supplementary material can be found online at https://doi.org/10.22434/IFAMR2019.0218

Table S1. Market simulation results for the introduction of a GMO-free label at a farmers' market.

Table S2. Market simulation results for the introduction of a certified GMO-free label at a farmers' market (fresh products and plants).

Table S3. Market simulation results for the introduction of a certified GMO-free label at a farmers' market (fresh products).

\section{Acknowledgements}

This research was funded via a grant from the USDA/Connecticut Specialty Crop Block Grant Program. 


\section{References}

Baker, G.A. 1998. Strategic implications of consumer food safety preferences - consumer concerns and willingness-to-pay. International Food and Agribusiness Management Review 1: 451-463.

Behe, B. 2006. Conjoint analysis reveals consumers prefer long, thin asparagus spears. HortScience 41: 1259-1262.

Behe, B.K., B.L. Campbell, H. Khachatryan, C. Hall, J. Dennis, P.T. Huddleston and R.T. Fernandez. 2014. Incorporating eye tracking technology and conjoint analysis to better understand the green industry consumer. HortScience 49: 1550-1557.

Behe, B.K., R.M. Walden, M. Duck, B. Cregg, K. Kelley and R.D. Lineberger. 2005. Consumer preferences for and cost of production of tabletop Christmas trees. HortScience 40: 409-412.

Bretton-Clark. 1992. Conjoint analyzer, version 3 (software). Bretton-Clark, Morristown, NJ, USA.

Campbell, B.L., I. Lesschaeve, A.J. Bowen, S.R. Onufrey and H. Moskowitz. 2010. Purchase drivers of Canadian consumers of local and organic produce. HortScience 45: 1480-1488.

Campbell, B.L., R.G. Nelson, R.C. Ebel and W.A. Dozier. 2006. Mandarin attributes preferred by consumers in grocery stores. HortScience 41: 664-670.

Campbell, B.L., S. Mhlanga and I. Lesschaeve. 2013. Consumer preference for peach attributes: market segmentation analysis and implications for new marketing. Agricultural and Resource Economics Review 42: 518-541.

Campbell, B.L., S. Mhlanga and I. Lesschaeve. 2016. Market dynamics associated with Canadian ethnic vegetable production. Agribusiness: an International Journal 32: 64-78.

Connecticut General Assembly (CGA). 2011. Committee bill no. 5508. CGA, Hartford, CT, USA. Available at: https://www.cga.ct.gov/2011/TOB/H/2011HB-05508-R01-HB.htm

Connecticut General Assembly (CGA). 2013. Committee bill no. 6527. CGA, Hartford, CT, USA. Available at: https://www.cga.ct.gov/2013/ACT/pa/pdf/2013PA-00183-R00HB-06527-PA.pdf

Consumer Reports. 2015. The cost of organic food. Consumer Reports, Yonkers, NY, USA. Available at: http://www.consumerreports.org/cro/news/2015/03/cost-of-organic-food/index.htm

Costa-Font, M., J.M. Gil and W.B. Traill. 2008. Consumer acceptance, valuation of and attitudes towards genetically modified food: review and implications for food policy. Food Policy 33: 99-111.

Costanigro, M. and J.L. Lusk. 2014. The signaling effect of mandatory labels on genetically engineered food. Food Policy 49: 259-267.

Darby, K., M.T. Batte, S. Ernst and B. Roe. 2008. Decomposing local: a conjoint analysis of locally produced foods. American Journal of Agricultural Economics 90: 476-486.

Ekelund, L., F. Ferqvist and H. Tjärnemo. 2007. Consumer preference for domestic and organically labelled vegetables in Sweden. Food Economics - Acta Agriculturae Scandinavica 4: 229-236.

Flagg, L.A., B. Sen, M. Kilgore and J.L. Locher. 2013. The influence of gender, age, education, and household size on meal preparation and food shopping responsibilities. Public Health Nutrition 17: 2061-2070.

Frank, C.A., R.G. Nelson, E.H. Simonne, B.K. Behe and A.H. Simonne. 2001. Consumer preferences for color, price, and vitamin c content of bell peppers. HortScience 36: 795-800.

Golan, E. and F. Kuchler. 2011. The effect of GM labeling regime on market outcome. Genetically modified food and global welfare. In: H. Beladi and E.K. Choi (eds.) Frontiers of economics and globalization. Vol. 10. Emerald Publishing Pty Limited, Melbourne, Australia.

Hair Jr., J.F., R.E. Anderson, R.L. Tatham and W.C. Black. 1998. Multivariate data analysis, $5^{\text {th }}$ edition. Prentice Hall, Upper Saddle River, NJ, USA.

Hall, C., B. Campbell, B. Behe, C. Yue, J. Dennis and R. Lopez. 2010. The appeal of biodegradable packaging to floral consumers. HortScience 45: 583-591.

Heslop, L.A. 2006. If we label it, will they care? The effect of GM-ingredient labelling on consumer responses. Journal of Consumer Policy 29: 203-228.

Kalaitzandonakes, N., L.A. Marks and S.S. Vickner. 2005. Sentiments and acts towards genetically modified foods. International Journal of Biotechnology 7: 161-177. 
Liaukonyte, J., N.A. Streletskaya, H.M. Kaiser and B.J. Rickard. 2013. Consumer response to 'contains' and 'free of' labeling: evidence from lab experiments. Applied Economic Perspectives and Policy 35: 476-507.

Lusk, J.L. and T.C. Schroeder. 2004. Are choice experiments incentive compatible? A test with quality differentiated beef steaks. American Journal of Agricultural Economics 86: 467-482.

Lusk, J.L., M. Jamal, L. Kurlander, M. Roucan and L. Taulman. 2005. A meta-analysis of genetically modified food valuation studies. Journal of Agricultural and Resource Economics 30: 28-44.

Mason, S., T. Starman, R.D. Lineberger and B.K. Behe. 2008. Consumer preferences for price, color harmony and care information of container gardens. HortScience 43: 380-384.

Nelson, R.G., C.M. Jolly, M.J. Hinds, Y. Donis and E. Prophete. 2005. Conjoint analysis of consumer preferences for roasted peanut products in Haiti. Journal of Consumer Studies 29: 208-215.

Non-GMO Project. 2019. History. Non-GMO Project, Bellingham, WA, USA. Available at: https://www. nongmoproject.org/about/history/

Noussair, C., S. Robin and B. Ruffieux. 2002. Do consumers not care about biotech foods or do they just not read the labels? Economics Letters 75: 47-53.

Noussair, C., S. Robin and B. Ruffieux. 2003. Do consumers really refuse to buy genetically modified food? The Economic Journal 114: 102-120.

Onozaka, Y. and D.T. McFadden. 2011. Does local labeling complement or compete with other sustainable labels? A conjoint analysis of direct and joint values for fresh produce claims. American Journal of Agricultural Economics 93(3): 693-706.

Organic Trade Association. 2019. GMO labeling. Organic Trade Association, Washington, DC, USA. Available at: https://ota.com/advocacy/gmos/gmo-labeling

Radelat, A. 2016. Senate moves to quash CT's GMO food labeling law. The CT Mirror. Available at: http:// ctmirror.org/2016/07/06/senate-poised-to-quash-connecticuts-gmo-food-labeling-law

Salisbury, K., K. Curtis, V. Pozo and C. Durward. 2018. Is local produce really more expensive? A comparison of direct market and conventional grocery produce pricing. Journal of Food Distribution Research 49(1): 13-21.

U.S. Census Bureau. 2011a. State and county quickfacts: Connecticut. U.S. Census Bureau, Washington, DC, USA. Available at: http://quickfacts.census.gov/qfd/states/09000.html

U.S. Census Bureau. 2015. Census Bureau releases 2010 census demographic profiles for Alaska, Arizona, California, Connecticut, Georgia, Idaho, Minnesota, Montana, New Hampshire, New York, Ohio, Puerto Rico and Wisconsin. U.S. Census Bureau, Washington, DC, USA. Available at: https://www. census.gov/newsroom/releases/archives/2010_census/cb11-cn137.html

Wolfe, A. 2013. Christine Lagarde: on top of the world. Wall Street Journal, October 4, 2013.

Wuepper, D., P. Wree and G. Ardali. 2018. Does information change German consumers' attitudes about genetically modified food? European Review of Agricultural Economics 46: 53-78.

Zagaden, Y., B.K. Behe and R. Gough. 2008. Consumer preferences for native plants in Montana residential landscapes and perceptions for naturalistic designs. Journal of Environmental Horticulture 26: 109-114.

Zepeda, L. 2009. Which little piggy goes to market? Characteristics of US farmers' market shoppers. International Journal of Consumer Studies 33: 250-257. 